\title{
PROPERTIES OF BULK AND SHEET MICRO-, SUBMICRO-, AND NANOCRYSTALLINE ALLOY 718
}

\author{
Shamil Mukhtarov ${ }^{1}$, Vener Valitov ${ }^{1}$, Nadya Dudova $^{1}$ \\ ${ }^{1}$ Institute for Metals Superplasticity Problems; 39 Khalturin Street; Ufa, 450001, Russia \\ Keywords: Submicro-, Nanocrystalline structure, Isothermal rolling, Superplasticity, Mechanical \\ properties.
}

\begin{abstract}
The superplastic properties of different semi-products out of Alloy 718 with microcrystalline (MC), submicrocrystalline (SMC) and nanocrystalline (NC) structures processed by severe plastic deformation and rolling have been studied. The alloy with SMC and NC structures can exhibit features of low temperature superplasticity. With decreasing the mean grain size of the Alloy 718 the temperature boundary of superplasticity becomes lower, the flow stress reduces and the ductility increases. The studies of the gauge portion of samples have shown that due to low temperature superplastic deformation there occur the following changes in the microstructure, namely, the density of dislocations decreases, non-equilibrium grain boundaries transforms to equilibrium ones and its mean grain size increases slightly. The boundaries of some grains have a banded contrast, which is apt to equilibrium high angle grain boundaries. The studies of the NC structure of Alloy 718 samples from superplastic deformation performed at different levels in various zones allowed revealing deformation bands indicating the occurrence of cooperative grain boundary sliding. The specific feature of the NC structure is a more uniform strain distribution and a less block size of cooperative grains as compared to SMC and MC structures.
\end{abstract}

The comparative analysis of the structure and the mechanical properties of bulk and sheet Alloy 718 after superplastic deformation and heat treatment has been carried out. It has been shown that performance of standard heat treatment provides obtaining mechanical properties corresponding to standard requirements.

\section{Introduction}

Technological plasticity is an important property for fabrication of parts from nickel based alloys. One way to enhance the technological plasticity is processing of SMC and NC structures in these alloys [1-2]. Realization of the effect of low temperature superplasticity becomes possible in case of the processed SMC and NC structural states. Such structures can be produced using severe plastic deformation (SPD) technique, such as multiple forging (MF) [2]. Superplastic (SP) properties of MC, SMC, NC bulk Alloy 718 were reported in [3], but microstructure changes after SP deformation were not investigated. This alloy is also widely used for production of sheets. That is why investigations aimed at the studies of mechanisms of processing SMC structure in sheet blanks by rolling, as well as of the effect of the processed structural conditions on the properties of bulk and sheet semi-products from Alloy 718 are rather urgent. The aim of the present work is to evaluate the effect of the produced MC, SMC, NC structures in bulk and sheet semi-products of Alloy 718 on its superplastic behavior, structural changes and mechanical properties. 


\section{Materials and Experimental Procedure}

The chemical composition of the alloys that were used in this work is shown in Table I. Samples of Alloy 718 were machined from 200 and $250 \mathrm{~mm}$ diameter billet. Alloy 718 billet $(200 \mathrm{~mm}$ in diameter) (SNECMA, ISTC\#104) was used for fabricating bulk billets. Alloy 718-ID $250 \mathrm{~mm}$ diameter billet (produced by "Electrostal", Russia) was used for fabrication of sheet blanks. The $200 \mathrm{~mm}$ billet was triple melted (VIM+ESR+VAR), and the $250 \mathrm{~mm}$ billet was double melted (VIM+VAR).

Table I. Composition of the Alloys that Were Studied (Wt. \%)

\begin{tabular}{|c|c|c|c|c|c|c|c|c|c|c|}
\hline & $\mathrm{Cr}$ & $\mathrm{Al}$ & $\mathrm{Ti}$ & $\mathrm{Fe}$ & $\mathrm{Nb}$ & $\mathrm{Mo}$ & $\mathrm{Co}$ & $\mathrm{B}$ & $\mathrm{C}$ & $\mathrm{Ni}$ \\
\hline Alloy 718 & 19 & 0.5 & 0.9 & 18.5 & 5.1 & 3.0 & 0.1 & 0.025 & 0.04 & Balance \\
\hline Alloy 718-ID & 18.9 & 0.5 & 1.0 & 18.4 & 5.08 & 3.1 & 0.03 & 0.004 & 0.05 & Balance \\
\hline
\end{tabular}

Bulk samples (40-80 $\mathrm{mm}$ in diameter and 10-12 mm long), were generated with MC, SMC and NC structures on 100 and 630 ton-force presses using SPD by MF on flat dies over the range of deformation temperatures $925-600{ }^{\circ} \mathrm{C}$ [3]. Sheet samples were produced by rolling of the bulk semi-product (100x50x9 mm in dimensions) of the microcrystalline Alloy 718-ID. Rolling was performed using six-high mill for isothermal rolling, model Lis-6/200 at $800-700{ }^{\circ} \mathrm{C}$, the maximum load exerted on the rolls being no more than 30 tons. The material was rolled to sheet shape of $0.9 \mathrm{~mm}$ in thickness. Tensile mechanical and SP characteristics were measured using sheet samples, with gauge dimensions of $12 \times 5 \times 2 \mathrm{~mm}$ for bulk material and $12 \times 5 \times 0.9 \mathrm{~mm}$ for sheet material. Test specimens were cut from the sheet material, their direction being parallel to rolling and transverse ones. Transmission electron microscope (TEM) investigations of deformed samples were performed using a JEM-2000EX.

\section{Experimental Results}

\section{Initial Alloy 718 Microstructure}

The initial microstructure of the hot forged Alloy 718 described in detail elsewhere [3] presented the fully recrystallized structure and had $\gamma$-phase grain size of about $40 \mu \mathrm{m}$ within which $\gamma^{\prime \prime}$ phase in the shape of discs was uniformly precipitated (Figure 1a).

The microstructure of the hot forged Alloy 718-ID (of "Electrostal" production) was coarsegrained. An average grain size in the central portion in the rod cross-section was about $45 \mu \mathrm{m}$ (Figure 1b). At the periphery the structure was non-uniform. Along with coarse grains up to 140 $\mu \mathrm{m}$ in size there occurred zones with grain sizes of $10 \mu \mathrm{m}$.

Formation of Micro-, Submicro- and Nanocrystalline Structures in Bulk Semi-Products

Microcrystalline fully recrystallized structure generated at the temperatures of MIF in the range of $925-850{ }^{\circ} \mathrm{C}$ and reported in [3] is shown in Figure 2a. The average grain size of $\gamma$-phase is 1.5 $\mu \mathrm{m}$. The structure has plates of $\delta$-phase and carbides that are uniformly distributed throughout the whole material volume, the width of $\delta$-phase plates being $0.5 \mu \mathrm{m}$ and length $-1-2 \mu \mathrm{m}$. The average size of carbides is $7 \mu \mathrm{m}$. This structure condition of the material was used for fabrication of bulk SMC and NC samples from Alloy 718 subjected to MF, and sheet samples with SMC structure were produced by rolling from Alloy 718-ID. Stepwise decrease of MF temperature to $700^{\circ}$ and $600^{\circ} \mathrm{C}$ provided the generation of duplex $(\gamma+\delta)$, and, correspondingly, SMC and NC structures with an average grain sizes of 0.3 and 0.08 [3], these structure are shown in Figures 
$2 \mathrm{~b}$, c. The dislocation density and the amount of non-equilibrium boundaries increase with decreasing processing temperature.

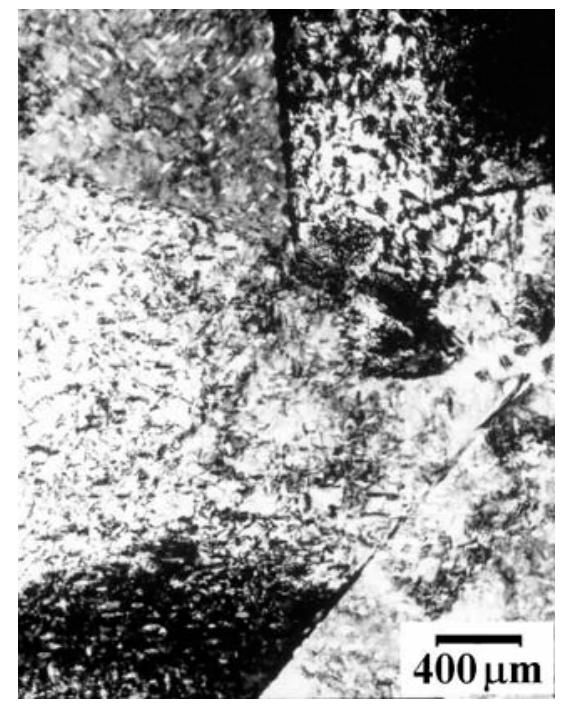

(a)

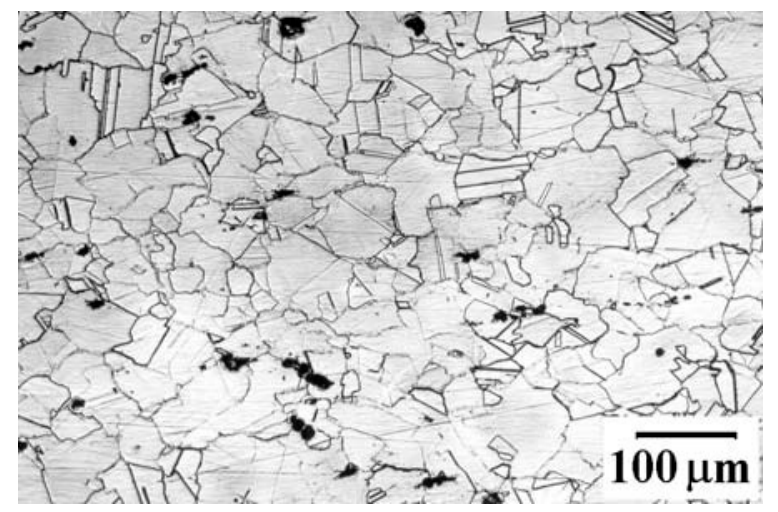

(b)

Figure 1. Microstructure of the (a) Alloy 718 (TEM), (b) Alloy 718-ID in the initial condition.

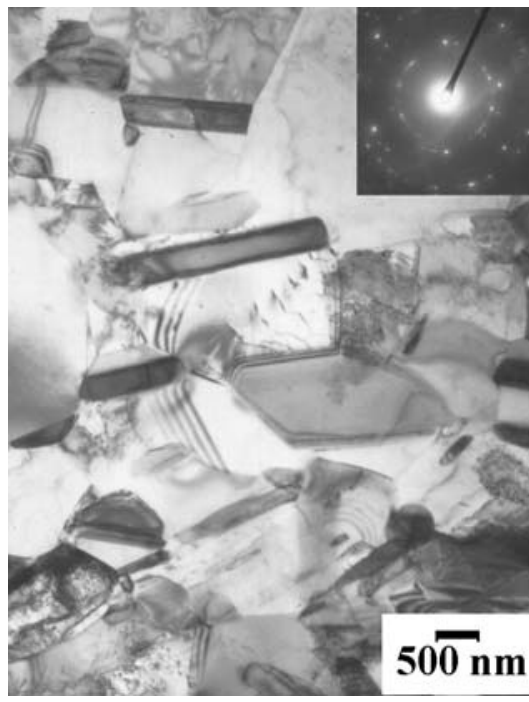

(a)

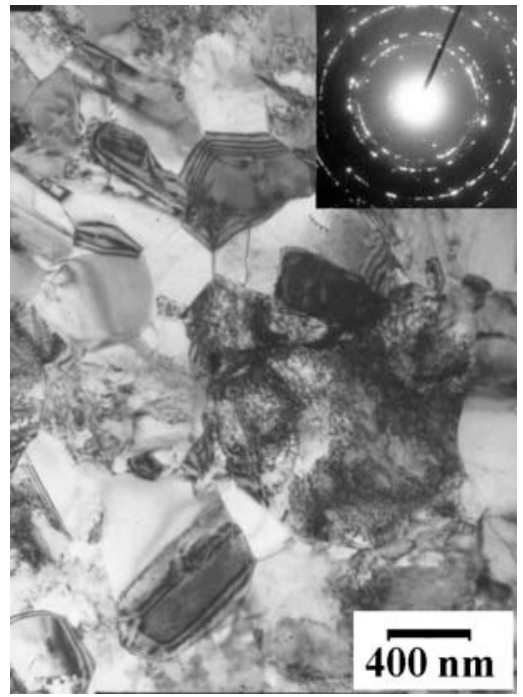

(b)

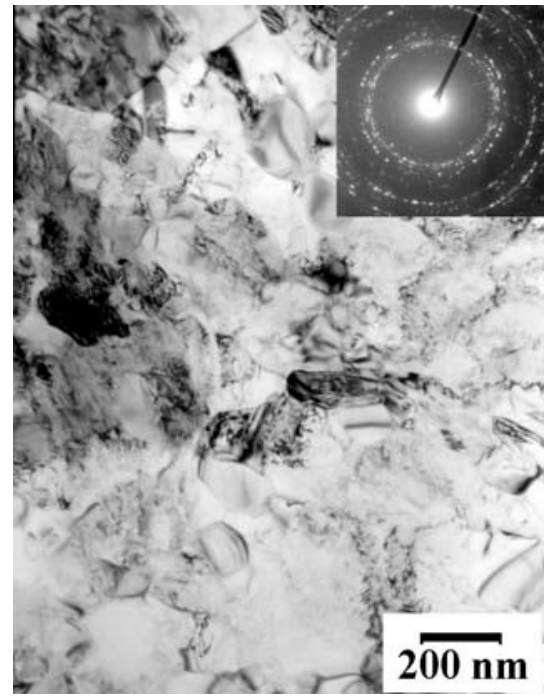

(c)

Figure 2. Microstructure of the Alloy 718 after multiple forging with (a) MC, (b) SMC, (c) NC condition (TEM).

\section{$\underline{\text { Formation of Submicrocrystalline Structure in Sheet Semi-Products }}$}

The studies of microstructure changes of Alloy 718-ID after isothermal rolling with temperature lowering from 800 to $700^{\circ} \mathrm{C}$ showed that at the initial stage of plastic deformation the cellular and sub-grain structures were generated, and with increasing strain there occurred the transformation of this structure into a granular one with high-angle boundaries. Both deformed structure and separate new recrystallized SMC grains were observed in the structure. With increasing strain the formation of low-angle boundaries is observed within the particles of $\delta$ phase, these boundaries divide a particle into several portions. Most plates of $\delta$-phase acquire a 
rounded shape. Dynamic recrystallization results in gradual generation of uniform structure with an average grain size of $0.5 \mu \mathrm{m}$ (Figure 3). The studies of the alloy thin structure have showed that the grains of $\gamma$-phase have higher dislocation density that is several times larger than that of the bulk alloy [3], that has been due to lower strains obtained during rolling.

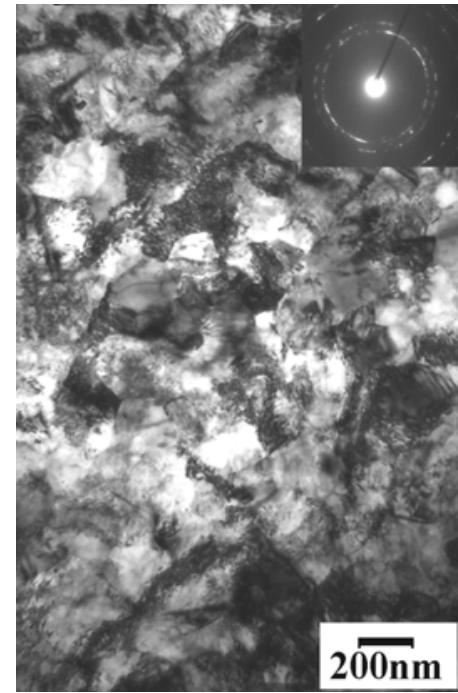

(a)

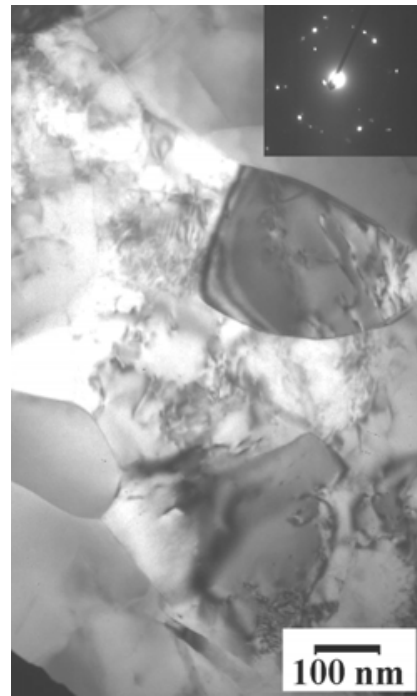

(b)

Figure 3. Microstructure of Alloy 718 after isothermal rolling at $700^{\circ} \mathrm{C}$.

Superplastic Properties of Micro-, Submicro-, and Nanocrystalline Alloy 718 and Alloy 718-ID

V.A. Valitov et al. [3] reported the results of superplastic properties of the Alloy 718 with MC and SMC structures in the bulk semi-product (Table II). Some of these results in the form of a plot, with strain rate $5.5 \times 10^{-4} \mathrm{~s}^{-1}$, are presented in Figure 4.

The results of superplasticity tests of the sheet semi-product from Alloy 718-ID with SMC structure were analyzed to show that over the temperature-strain rate range investigated the alloy manifested superplasticity characteristics (Table II). It is evident that the properties of test samples in two inter-perpendicular directions under the same deformation conditions are only slightly different. The longitudinal specimens possess higher values of flow stresses $\sigma_{40}$, and $\delta$ by $3 \ldots 10 \%$ and $5 \ldots 25 \%$, respectively. The obtained results on superplasticity properties show that these results are similar to those received on samples produced by multiple forging. Additionally the superplasticity properties of the alloy with NC structure (see Table III) were obtained, these data confirm the following trend: the reduced grain size provides the reduction of the lower temperature limit for superplasticity.

\section{Microstructure Changes in a Bulk MC Semi-Product after SP Deformation}

Microstructure changes were investigated in test specimens after SP deformation in tension of Alloy 718 with $\mathrm{MC}$ structure at temperatures ranging from 700 to $980^{\circ} \mathrm{C}$ and strain rates from $1.5 \times 10^{-4}$ to $5.5 \times 10^{-3} \mathrm{~s}^{-1}$ to show that within the temperature range of $700-800^{\circ} \mathrm{C}$ the structure changes were not observed.

After SP deformation with strain rate $5.5 \times 10^{-4} \mathrm{~s}^{-1}$ and increase in temperature from 900 to $980^{\circ} \mathrm{C}$ the increase in the average size of $\gamma$-phase grains from 3 to $6 \mu \mathrm{m}$ and dissolution of $\delta$-phase are observed. The occurrence of pores was revealed on gauge portion of samples (Figures 5-6). The 
sizes of pores and their pile-ups also increase with increasing deformation temperature. If at $900^{\circ} \mathrm{C}$ the width of pores and pile-ups was from 5 to $10 \mu \mathrm{m}$, the length of separate pores - no more than $20 \mu \mathrm{m}$, then after deformation at $980{ }^{\circ} \mathrm{C}$ the length of pile-ups became more than 150 $\mu \mathrm{m}$. Pores and their pile-ups are uniformly arranged along the whole volume of the deformed material and are elongated along the direction of sample straining. The largest number of pores was observed at $980{ }^{\circ} \mathrm{C}$, especially in the zone of sample rupture (Figure 6).

Table II. SP Properties of Bulk Alloy 718 and Sheet Alloy 718-ID Semi-Products The Stress $\sigma_{40}$ is the Stress at a Plastic Strain of $40 \%$

\begin{tabular}{|c|c|c|c|c|c|c|}
\hline \multicolumn{2}{|c|}{ Grain (particle) size, $\mu \mathrm{m}$} & \multirow{2}{*}{$\begin{array}{c}\text { Temperature, } \\
{ }^{\circ} \mathrm{C}\end{array}$} & \multirow[t]{2}{*}{ Strain rate, $\mathrm{s}^{-1}$} & \multirow{2}{*}{$\begin{array}{c}\sigma_{40} \\
\mathrm{MPa}\end{array}$} & \multirow{2}{*}{$\begin{array}{l}\delta \\
\%\end{array}$} & \multirow[b]{2}{*}{$\mathrm{m}$} \\
\hline$\gamma$-phase & $\delta$-phase & & & & & \\
\hline $\begin{array}{c}0.3 \text { (Bulk) } \\
{[3]}\end{array}$ & $0.1-0.3$ & $\begin{array}{l}950 \\
900 \\
800 \\
700\end{array}$ & $\begin{array}{l}5.5 \times 10^{-4} \\
5.5 \times 10^{-4} \\
5.5 \times 10^{-4} \\
5.5 \times 10^{-4}\end{array}$ & $\begin{array}{c}48 \\
65 \\
123 \\
250\end{array}$ & $\begin{array}{l}650 \\
790 \\
580 \\
440\end{array}$ & $\begin{array}{c}0.7 \\
0.69 \\
0.5 \\
0.35\end{array}$ \\
\hline \multirow{8}{*}{0.5 (Sheet) } & \multirow{8}{*}{$0.1-0.5$} & 950 & $5.5 \times 10^{-4}$ & 51 & 490 & $-\mathrm{L}^{*}$ \\
\hline & & \multirow{2}{*}{900} & \multirow{2}{*}{$5.5 \times 10^{-3}$} & 142 & 560 & $-\mathrm{L}$ \\
\hline & & & & 111 & 540 & $-\mathrm{T}$ \\
\hline & & 900 & $10^{-3}$ & 86 & 820 & $0.5 \mathrm{~L}$ \\
\hline & & 900 & $5.5 \times 10^{-4}$ & 68 & 720 & $0.65 \mathrm{~L}$ \\
\hline & & 800 & $3 \times 10^{-4}$ & 115 & 550 & $-\mathrm{T}$ \\
\hline & & \multirow{2}{*}{700} & \multirow{2}{*}{$5.5 \times 10^{-4}$} & 284 & 380 & $-\mathrm{L}$ \\
\hline & & & & 271 & 350 & $-\mathrm{T}$ \\
\hline
\end{tabular}

* L-Longitudinal sheet direction. T-Transverse sheet direction.

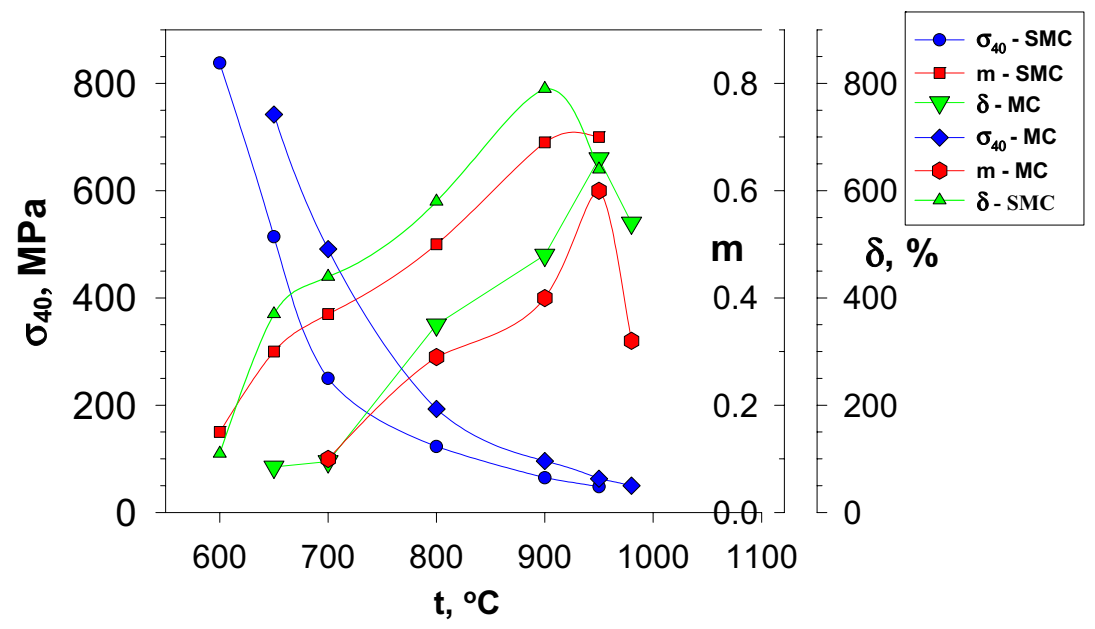

Figure 4. Superplasticity properties of Alloy 718 with MC $(1 \mu \mathrm{m})$ and SMC $(0.3 \mu \mathrm{m})$ structures at strain rate of $5.5 \times 10^{-4} \mathrm{~s}^{-1}$.

\section{Microstructure Changes in SMC Semi-Products after SP Deformation}

The microstructure changes after deformation of Alloy 718 and Alloy 718-ID with SMC structure over the temperature range $600-950{ }^{\circ} \mathrm{C}$ with strain rate $5.5 \times 10^{-4} \mathrm{~s}^{-1}$ were analyzed to show that at deformation temperatures $600-700{ }^{\circ} \mathrm{C}$ the average grain size of $\gamma$-phase remained about the same, as shown in Figure 7a. 
With increasing the deformation temperature to $800,900,950{ }^{\circ} \mathrm{C}$ in the microstructure of the test specimen the increase of an average size of $\gamma$-phase grains up to $0.6,0.8,2 \mu \mathrm{m}$, respectively, and some dissolution of $\delta$-phase plates were revealed. Thus, after deformation at $950{ }^{\circ} \mathrm{C}$ the alloy becomes $\mathrm{MC}$. With increasing the deformation temperature the following changes occurred in the alloy structure: the quantity of equilibrium boundaries increases while the amount of nonequilibrium ones decreases, the density of dislocations becomes less dense both in the body and along grain boundaries (Figure 7).

Table III. SP Properties of the Alloy 718 in the NC Conditions

The Stress $\sigma_{40}$ is the Stress at a Plastic Strain of $40 \%$

\begin{tabular}{|c|c|c|c|c|c|}
\hline Grain size (plates), $\mu \mathrm{m}$ & Temperature, ${ }^{\circ} \mathrm{C}$ & Strain rate, $\mathrm{s}^{-1}$ & $\sigma_{40}, \mathrm{MPa}$ & $\delta, \%$ & $\mathrm{~m}$ \\
\hline \multirow{3}{*}{0.08} & 800 & $5.5 \times 10^{-4}$ & 128 & 380 & 0.4 \\
& 700 & $3 \times 10^{-4}$ & 230 & 690 & 0.4 \\
& 650 & $3 \times 10^{-4}$ & 310 & 405 & 0.34 \\
& 600 & $3 \times 10^{-4}$ & 652 & 250 & 0.35 \\
\hline
\end{tabular}

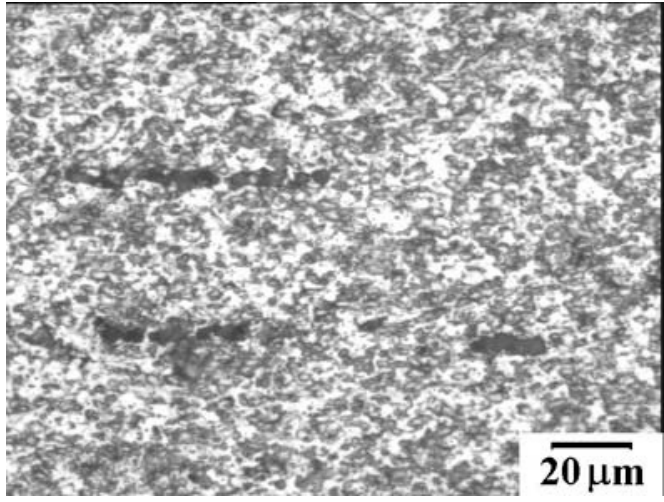

(a)

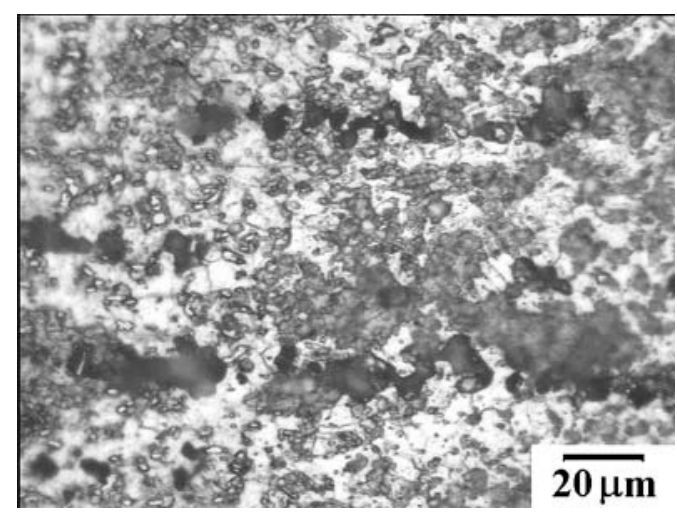

(b)

Figure 5. Microstructure of Alloy 718 with MC structure subjected to tension at (a) $900{ }^{\circ} \mathrm{C}$, (b) $950{ }^{\circ} \mathrm{C}$ with strain rate $5.5 \times 10^{-4} \mathrm{~s}^{-1}$.

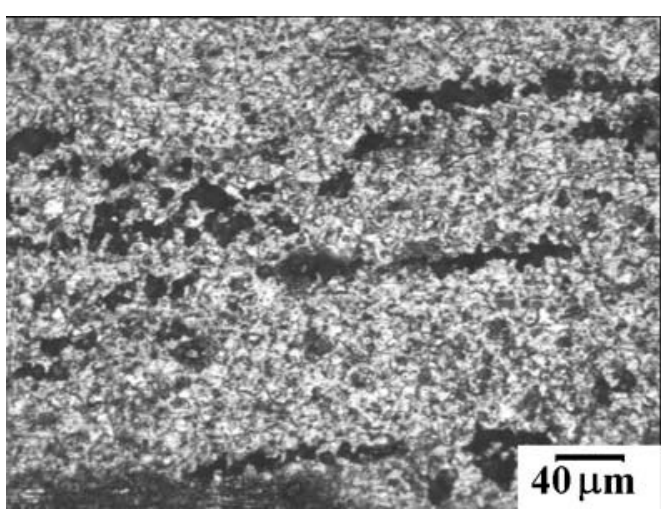

(a)

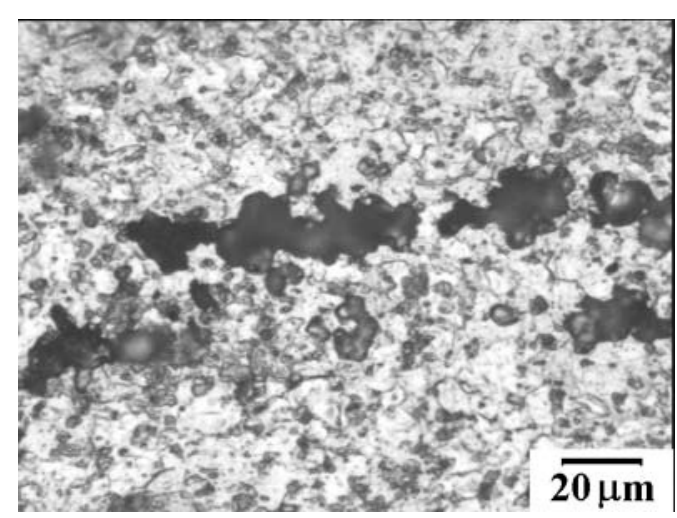

(b)

Figure 6. Microstructure of Alloy 718 with MC structure subjected to tension at $980^{\circ} \mathrm{C}$ with strain rate $5.5 \times 10^{-4} \mathrm{~s}^{-1}$ in the vicinity of specimen fracture zone.

At $900^{\circ} \mathrm{C}$ the formation of pores was revealed. Pores and chains of pores are observed along the whole specimen's gauge length, they are elongated in the direction of specimen's tension 
direction. But the size of pores and their quantity in SMC alloy is less than in the alloy with MC structure. With distance from the fracture zone only separate pores are observed. The width of pores is no more than $5 \mu \mathrm{m}$ and the length does not exceed $8 \mu \mathrm{m}$. The length of pile-ups - no more than $70 \mu \mathrm{m}$ (Figure 8).

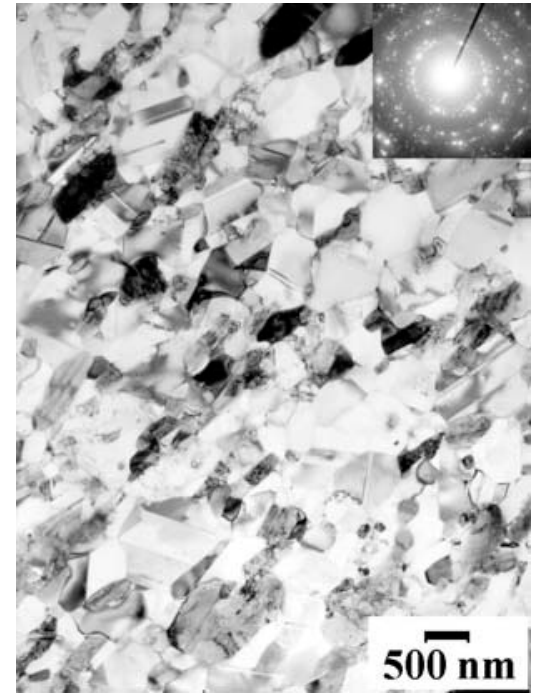

(a)

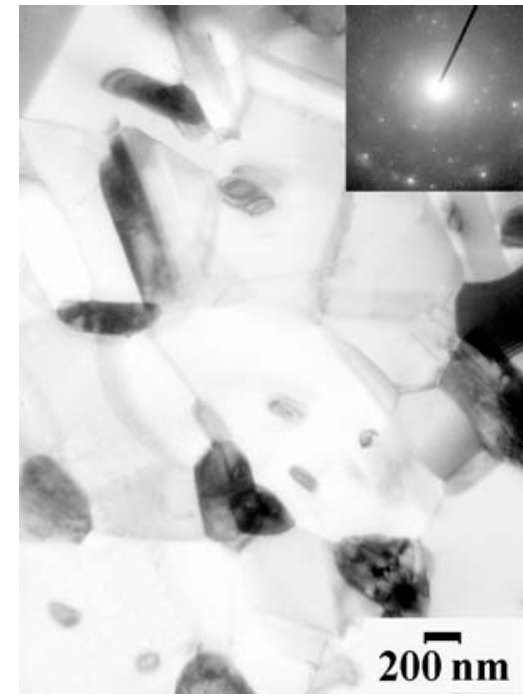

(b)

Figure 7. Microstructure and electron-diffraction pattern of Alloy 718 subjected to tension (a) at $700^{\circ} \mathrm{C}$, (b) at $800^{\circ} \mathrm{C}$ with strain rate $5.5 \times 10^{-4} \mathrm{~s}^{-1}$.

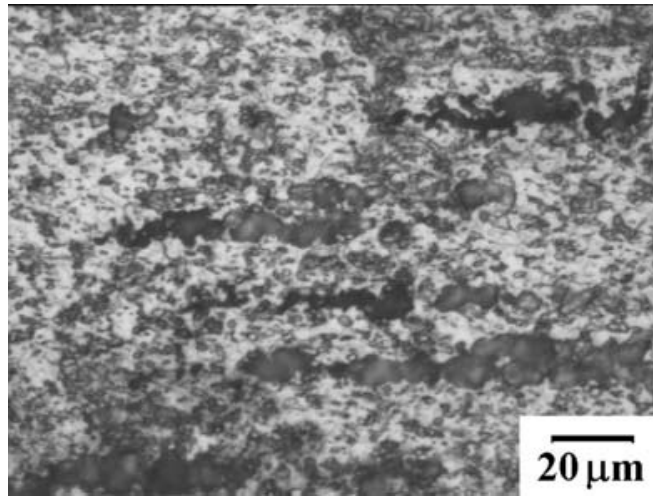

(a)

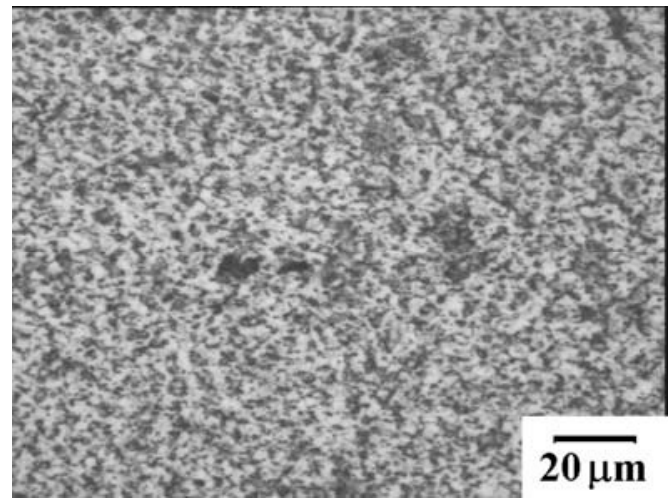

(b)

Figure 8. Microstructure of Alloy 718 subjected to tension at $900^{\circ} \mathrm{C}$ with strain rate $5.5 \times 10^{-4} \mathrm{~s}^{-1}$ : (a) sample's gauge zone; (b) near sample's grip section.

\section{$\underline{\text { Microstructure Changes in a Bulk NC Semi-Product after SP Deformation }}$}

The studies of microstructure changes after deformation of Alloy 718 with NC structure at temperatures ranging from 550 to $700{ }^{\circ} \mathrm{C}$ and strain rates from $0.9 \times 10^{-4}$ to $5.5 \times 10^{-4} \mathrm{~s}^{-1}$ showed that at deformation temperatures $550{ }^{\circ} \mathrm{C}$ an average grain size did not practically change (Figure 9a). The structure has areas with recrystallized grains and areas possessing high dislocation density in bodies of grains and in $\delta$-phase As the deformation temperature increases from 600 to $700{ }^{\circ} \mathrm{C}$ at strain rate of $3 \times 10^{-4} \mathrm{~s}^{-1}$ an average grain size of $\gamma$-phase increases from 0.15 to $0.3 \mu \mathrm{m}$, i.e. grows to SMC structure, the amount of high-angle boundaries increases, while the density of dislocations decreases (Figure 9). 
The studies of surface relief of Alloy 718 samples with NC, SMC and MC structures after superplastic deformation revealed the occurrence of deformation bands that divided the structure into separate blocks the sizes of which being approximately 5-10 times larger than the size of individual grains (Figure 10).

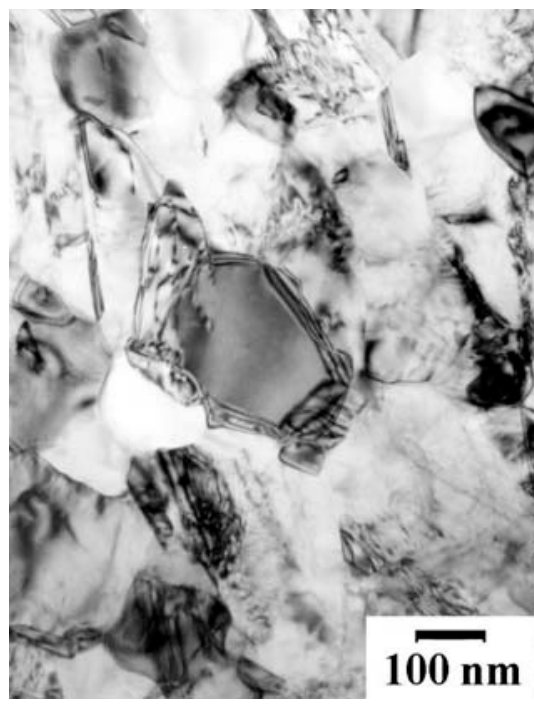

(a)

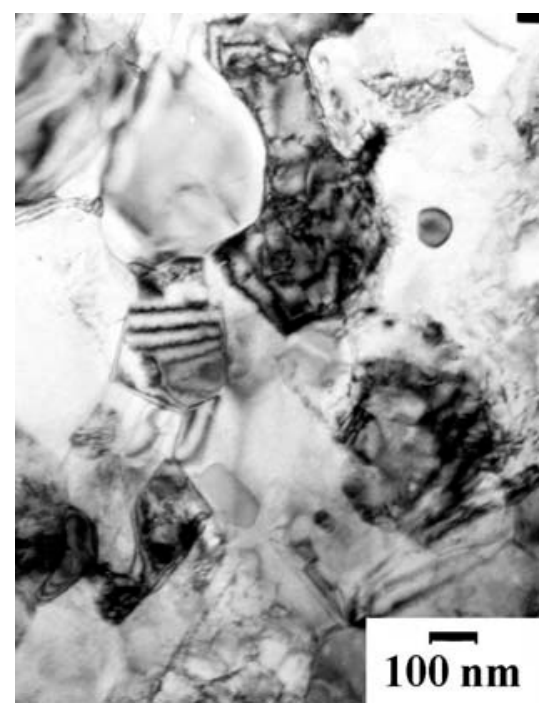

(b)

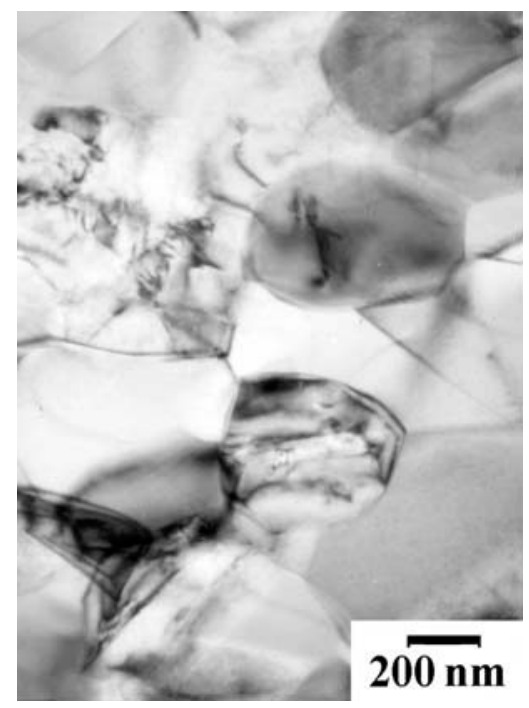

(c)

Figure 9. Microstructure of Alloy 718 with NC structure subjected to tension: (a) at $550^{\circ} \mathrm{C}$ with strain rate $0.9 \times 10^{-4} \mathrm{~s}^{-1}$; (b) at $600^{\circ} \mathrm{C}$; (c) at $700^{\circ} \mathrm{C}$ with strain rate $3 \times 10^{-4} \mathrm{~s}^{-1}$.

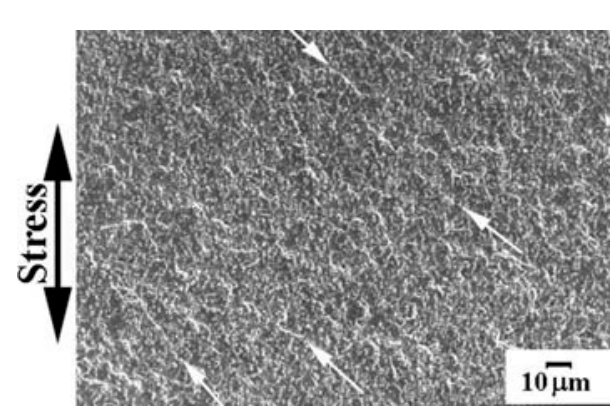

(a)

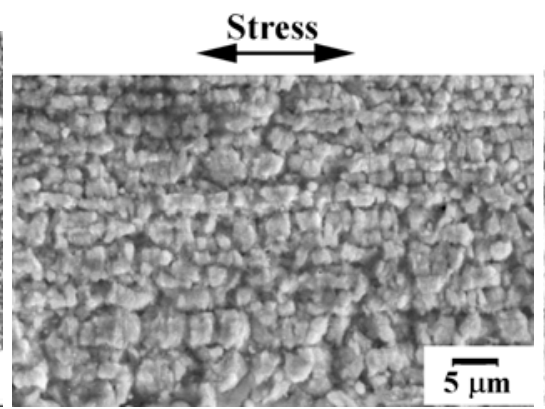

(b)

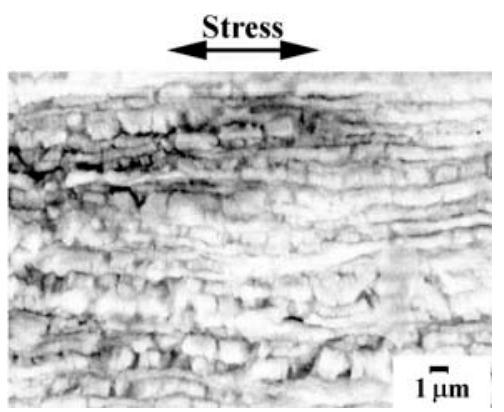

(c)

Figure 10. Relief of Alloy 718 sample surface (SEM) after superplastic deformation by tension: (a) with MC structure $(1,5 \mu \mathrm{m})$ at $925^{\circ} \mathrm{C}$ with strain rate $5.5 \times 10^{-4} \mathrm{~s}^{-1}$ and strain $100 \%$; (b) with SMC structure $(0.3 \mu \mathrm{m})$ at $700{ }^{\circ} \mathrm{C}$ with strain rate $3 \times 10^{-4} \mathrm{~s}^{-1}$; (c) with $\mathrm{NC}$ structure $(0.08 \mu \mathrm{m})$ at $600^{\circ} \mathrm{C}$ with strain rate $1.5 \times 10^{-4} \mathrm{~s}^{-1}$.

\section{Mechanical Properties after Heat Treatment}

The studies of microstructure after carrying out the standard heat treatment [4] of sheet SMC Alloy 718 showed that it resulted in the generation of uniform structure, an average grain size of $\gamma$-phase being $25 \mu \mathrm{m}$. Test specimens from the heat treated sheet were cut in two directions longitudinal and transverse. The data on mechanical properties of Alloy 718-ID sheets are presented in Table IV. These data evidently correspond to the Specification requirements to the 
material. In the direction perpendicular to rolling direction (the transverse direction) all characteristics are a little bit lower than those in the rolling direction (the longitudinal direction). The difference in strength properties does not exceed $3 \%$, while that in plastic properties is $2 \ldots 10 \%$.

Table IV. Mechanical Properties of Alloy 718-ID Test Specimens after Rolling and Heat Treatment

\begin{tabular}{|c|c|c|c|c|c|c|}
\hline & \multicolumn{3}{|c|}{$20^{\circ} \mathrm{C}$} & \multicolumn{3}{c|}{$650{ }^{\circ} \mathrm{C}$} \\
\cline { 2 - 7 } & Long. & Trans. & AMS5662[5] & Long. & Trans. & AMS5662[5] \\
\hline $\begin{array}{c}\text { Ultimate Strength, } \\
\mathrm{MPa}\end{array}$ & 1350 & 1337 & 1276 & 1016 & 1016 & 1000 \\
\hline $\begin{array}{c}\text { Yield Strength, } \\
\mathrm{MPa}\end{array}$ & 1073 & 1058 & 1034 & 889 & 866 & 862 \\
\hline$\% \mathrm{El}$ & 23 & 25 & 10 & 15 & 13 & 10 \\
\hline$\% \mathrm{RA}$ & 23 & 23 & 15 & 17 & 16 & 15 \\
\hline
\end{tabular}

\section{Discussion}

The obtained results show that SMC structure in Alloy 718 can be achieved not only by MF but also by isothermal rolling of MC alloy. Formation of SMC structure during rolling apparently occurs both at MF processing [6], when the cellular, sub-grain structures are generated, and also during their transformation into granular structure.

SMC and NC structures formed in Alloy 718 provide the expansion of temperature - strain rate conditions of SP deformation. Thus, by lowering grain size by an order of magnitude the temperature can be lowered or the strain rate of SP deformation can be increased by an order of magnitude. At $700{ }^{\circ} \mathrm{C}$ the Alloy 718 with $\mathrm{NC}$ structure displays the same superplastic properties as the same alloy with SMC structure, while at $800^{\circ} \mathrm{C}$ the alloy superplastic properties are better than those of the alloy with $\mathrm{MC}$ structure. The latter could be associated with that during tests at $800{ }^{\circ} \mathrm{C}$ the grain size of the alloy with the initial NC structure is smaller than that in the alloy with the initial MC structure. Achievement of a finer more uniform structure in Alloy 718 billets provides the reduction of difference in wall thickness of parts during forming operations.

Microstructure studies of samples after superplastic deformation in tension showed the occurrence of pores formation in Alloy 718 at $900{ }^{\circ} \mathrm{C}$ that with increasing the deformation temperature became more intense in the fracture area and in the areas adjacent to fracture area. As the grain size in Alloy 718 decreased, the size of pores and their amount decreased also. An average size of pores in the SMC structure is about 2 times smaller than in MC structure.

The results of the studies of the deformation behaviour of Alloy 718 with MC, SMC and NC structures have been comparatively analyzed to show that there exist some regular mechanisms of superplastic behaviour that are inherent in all conditions, as well as some peculiar features that are characteristic of $\mathrm{NC}$ condition. In all cases the development of the processes cooperative grain boundary sliding occurs. As this takes place, the formation of blocks consisting of the cooperated grains is observed. The size of blocks in cross-section is approximately by 5-10 times larger than the size of individual grains for, respectively, NC, SMC or MC structures (Figure 10). Thus, for the structure conditions under investigation the size of blocks correlates with the initial grain size. It seems likely, that a finer size of blocks in the alloy with NC structure provides more uniform deformation distribution along the cross-section of a sample as compared with the deformation behaviour of the material with SMC or MC structures. 
The results of mechanical tests of samples after rolling and heat treatment demonstrated the good strength and plastic characteristics, both at room and elevated temperatures. Consequently, the standard heat treatment used for the alloys with coarse-grained and MC structures is suitable for the SMC Alloy 718.

\section{Conclusions}

1. The regimes for isothermal rolling of sheet blanks from Alloy 718 with uniform SMC structure $(\mathrm{d}=0.5 \mu \mathrm{m})$ were developed.

2. It has been established that SMC and NC structures formed in bulk and sheet semi-products from Alloy 718 provide the expansion of temperature - strain rate conditions of superplastic deformation. The lowered grain size in the alloy allows the decrease in temperature by an order of magnitude or the increase in strain rate of superplastic deformation by the same order. Both factors provide the reduction in cavitation during SP deformation as compared with MC structure.

3. The studies of the surface relief of Alloy 718 samples with MC, SMC and NC structures after superplastic deformation have revealed the presence of deformation bands that evidently points to the development of the processes of cooperative grain boundary sliding. In this case the size of blocks of cooperated grains in the alloy with NC structure is 5-10 times larger than the size of $\mathrm{NC}$ grains.

4. It has been established that after standard heat treatment of Alloy 718 the good strength and plastic characteristics were attained both at room and elevated temperatures that meet the Specification requirements of the material.

\section{Acknowledgements}

The authors would like to thank the colleagues from GE - CRD for long-term cooperation.

\section{References}

1. Oscar A. Kaibyshev, Superplasticity of Alloys, Intermetallides and Ceramics (Berlin: Springer Verlag, 1992), 316.

2. G. Salishcev, R. Zaripova, R. Galeev, O. Valiakhmetov, "Nanocrisalline structure formation during severe plastic deformation in metals and their deformation behavior," Nanostructured Materials, 6 (1994), 913-916.

3. V.A. Valitov et. al., "Processing and Properties of Microcrystalline, Submicrocrystalline and Nanocrystalline Alloy 718," Fifth International Special Emphasis Symposium on Superalloys 718, 625, 706, and Derivatives, ed. E.A. Loria (TMS, 2001), 313-321.

4. W.T. Chandler, A.K. Ghosh, W.M. Mahoney, "Superplastic forming and diffusion bonding of Inconel 718” J. Spacecraft, 21 (1) (1984), 61-64.

5. L.M. Bernshtein, A.P. Matevosian, V.S. Sandler, ed, Deformation and properties of aerospace material technique. Proceeding of International Conference (Moscow: Metallurgia, 1982), 376.

6. Sh. Kh. Mukhtarov et. al., "Formation of Submicrocrystalline and Nanocrystalline Structures in a Nickel-Iron Inconel 718 Alloy," Proceeding of VI International Conference Fizikohimia ultradespersnyh (nano-) system (Moscow: MIFI, 2003), 204-207. 